\title{
Danshensu attenuates aldosterone-induced cardiomyocytes injury through interfering p53 pathway
}

\author{
XIAOHONG YANG, RUI YANG, XIANLI LI and XIAOHUI ZHENG \\ Department of Cardiovascular, Anyang District Hospital, Anyang, Henan 455000, P.R. China
}

Received February 22, 2017; Accepted July 11, 2017

DOI: $10.3892 / \mathrm{mmr} .2017 .7137$

\begin{abstract}
Heart failure, characterized by impaired systolic and/or diastolic function, is a common cardiovascular disease. The loss of cardiomyocytes due to various factors, including through necrosis or apoptosis can result in heart failure. Previous studies have indicated that excessive aldosterone (ALD) serves an essential role in the process of heart failure, and the heart is also one of the direct targets of ALD, which can provoke hypertrophy and the apoptosis of cardiomyocytes. The aim of the present study was to investigate the protective effect of danshensu (DSS) on ALD-induced cardiomyocytes injury. The present results demonstrated that DSS increased cell viability and decreased the leakage of lactate dehydrogenase in cardiomyocytes exposed to ALD. In addition, DSS decreased the apoptotic rate of ALD-stimulated cells. Further research indicated that DSS- and cellular tumor antigen p53 (p53)-alone or combination treatment was able to decrease the expression levels of apoptosis regulator BAX and caspase-3, and increase the expression of apoptosis regulator B-cell lymphoma $(\mathrm{Bcl})-2$ in ALD-stimulated cardiomyocytes. Taken together, the results of the present study suggest that DSS inhibits the harmful effects of ALD on cardiomyocytes via interfering with the p53 signaling pathway. These results provide novel evidence for the potential protective effects of DSS.
\end{abstract}

\section{Introduction}

Cardiovascular disease is one of the most frequent diseases both in developed countries and developing countries (1). Heart failure, characterized by impaired systolic and/or diastolic function with high morbidity and mortality, is the common ending of diverse etiologies (2). It is well accepted that one of most important reasons resulting in heart failure is cardiomyocytes loss including necrosis and apoptosis (3). The

Correspondence to: Dr Xiaohui Zheng, Department of Cardiovascular, Anyang District Hospital, 260 Dengta Road, Anyang, Henan 455000, P.R. China

E-mail: zhengxiaohui41@163.com

Key words: cardiovascular disease, aldosterone, danshensu, cardiomyocytes, apoptosis process of apoptotic involves many factors like sympathetic nervous system, renin-angiotensin system, reactive oxygen species (ROS). Research evidences indicates that excessive aldosterone (ALD) plays a critical role in the process of heart failure, and heart is also one of direct targets of ALD, which can provoke hypertrophy and apoptosis of cardiomyocytes $(4,5)$. Previous research indicated that ALD could induce cardiomyocytes apoptosis mainly via $\mathrm{Ca}^{2+}$ overload mediated mitochondria-dependent and independent pathway (6). However, little is known about ALD is able to induce cardiomyocytes apoptosis via p53 signaling pathway.

Salvia miltiorrhiza (Danshen), a traditional medicine, is widely used in the treatment of cerebrovascular and cardiovascular diseases. Danshensu (DSS) is the major water-soluble component extracted from Salvia miltiorrhizae. Its chemical structure is 3-(3,4-dihydroxyphenyl)-2-hydroxypropanoic acid and could improve microcirculation, suppress the formation of ROS, inhibit platelet adhesion and aggregation, and protect myocardium against ischemia (7-9). It has been previously reported that DSS has pharmacological effects such as anti-atherosclerosis, anti-inflammatory, and anti-oxidative damage (10-12). However, the effect of DSS on ALD induced cardiomyocytes injury is still unclear especially through interfering p53 signaling pathway. Hence, the aim of present study was to investigate the protective effect of DSS on ALD-induced apoptosis in cardiomyocytes which mainly involve in the signaling pathway of p53.

\section{Materials and methods}

Chemicals and animals. DSS was purchased from National Food and Drug Testing Institute (Beijing, China). Dulbecco's modified Eagle's medium (DMEM) and fetal bovine serum (FBS) were purchased from Gibco; Thermo Fisher Scientific, Inc. (Waltham, MA, USA). Penicillin and streptomycin were purchased from Huirui Biotechnology Co., Ltd. (Xi'an, China). MTT was purchased from Invitrogen (Carlsbad, CA, USA). Protein quantification kit was purchased from Boster (Nanjing, China). Lactate dehydrogenase (LDH) assay kit was from BD Biosciences (San Jose, CA, USA). Caspase-3, Bax, B-cell lymphoma (Bcl)-2, and GAPDH antibodies were obtained from Santa Cruz Biotechnology (Santa Cruz, CA, USA). P53 antibody was from Abcam (Cambridge, MA, USA). Secondary antibodies were purchased from the Zhongshan Co. (Beijing, China). 
Sprague-Dawley (SD) rats (between 1-3 days old) were provided by the Experimental Animal Center of Henan. This study was performed according to the Guide for the Care and Use of Laboratory Animals published by the US National Institutes of Health (National Institutes of Health Publication, no. 85-23, revised in 1996).

Primary cultured rats' cardiomyocytes were isolated from SD rats according to previous methods (13). The purity of cultured cardiomycoytes were $99 \%$ as evaluated by immunofluoresence staining by cardiac muscle sarcomeric a-actin antibody (Boster Biotechnology Ltd., Wuhan, China) and showed in Fig. 1. Cardiomyocytes were kept in the serum-free medium for $12 \mathrm{~h}$ prior to the experiment and then stimulated by ALD as indicated. In the DSS treatment experiments, Cardiomyocytes were exposed to ALD $(10 \mu \mathrm{mol} / \mathrm{l})$ for $12 \mathrm{~h}$ after pretreated with the DSS for $2 \mathrm{~h}$.

Assessment of the viability of cardiomyocytes by MTT methods. The cells were exposed to different concentration of DSS for 12 or with the different concentration of ALD for $12 \mathrm{~h}$ or ALD at $10 \mu \mathrm{mol} / 1$ for indicated time, and the cells were subjected to ALD $(10.0 \mu \mathrm{mol} / \mathrm{l})$ treatment in the absence or presence of DSS. After indicated treatment, $20 \mu 1$ of $5 \mathrm{mg} / \mathrm{ml}$ MTT solution was added into and incubated at $37^{\circ} \mathrm{C}$ for $4 \mathrm{~h}$. Formazan salt crystals were then dissolved with $150 \mathrm{ml}$ dimethylsulfoxide for each well. The mixtures were assayed at $490 \mathrm{~nm}$ using a microplate reader (Bio-Rad Laboratories, Inc., Hercules, CA, USA).

Assayed the leakage of $L D H$. The cardiomyocytes were subjected to ALD $(10.0 \mu \mathrm{mol} / \mathrm{l})$ treatment in the absence or presence of DSS and then LDH activity was measured using the relative LDH activity assay kit according to the instruction of the kit. LDH leakage rate was expressed as the percentage of the total LDH activity (the extracellular LDH activity plus the intracellular LDH activity), according to the following equation: $\% \mathrm{LDH}$ release rate $=(\mathrm{LDH}$ activity in medium $/$ total LDH activity) $\mathrm{x} \%$.

Apoptosis assay. Then apoptotic cells were identified using an Annexin V/PI apoptosis kit (Nanjing KeyGen BioTech Co., Ltd., Nanjing, China) and flow cytometry. The cardiomyocytes were subjected to ALD $(10.0 \mu \mathrm{mol} / \mathrm{l})$ treatment in the absence or presence of DSS for $12 \mathrm{~h}$, about (1-1.5) $\times 10^{6}$ cells were harvested and re-suspended in $500 \mu 1$ binding buffer. Next, the cells were incubated with $5 \mu \mathrm{l}$ Annexin V-fluorescein isothiocyanate (FITC) and $5 \mu \mathrm{lPI}(50 \mathrm{mg} / \mathrm{ml})$ for $15 \mathrm{~min}$ in the dark and immediately analyzed by flw cytometry. Data from at least $2 \times 10^{5}$ cells of each sample were acquired and analyzed using Cell Quest software, version 7.5.3 (Becton Dickinson, Franklin Lakes, NJ, USA). In the PI vs. FITC scatter plot, the percentage of cells in the lower left quadrant (live cells), upper left quadrant (necrotic cells), upper right quadrant (late apoptotic cells) and lower right quadrant of (early apoptotic cells) was calculated for comparison.

Western blot analysis. The cardiomyocytes were pretreated with DSS and p53 specific inhibitor pifithrin- $\alpha$ alone or in combination for $2 \mathrm{~h}$ and then subjected to ALD $(10.0 \mu \mathrm{mol} / \mathrm{l})$ for $12 \mathrm{~h}$. After the treatment, the cardiomyocytes were washed

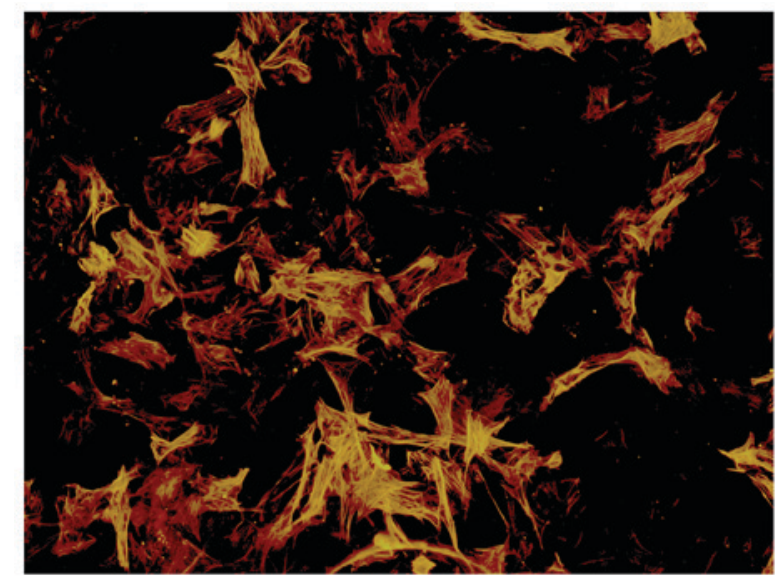

Figure 1. Characterization of primary cultured rats' cardiomyocytes derived from the male Sprague-Dawley rats. The cells were stained with cardiac muscle sarcomeric a-actin and labeled with the cy 3 conjugated antibody. The cells were observed at magnification of x 200 under a fluorescence microscope.

once in PBS and lysed on ice in lysis buffer (Beyotime Institute of Biotechnology, Jiangsu, China). The protein concentration was determined using a BCA protein assay kit. Equal amounts of proteins were subjected to $10 \%$ SDS-polyacrylamide gel. After being electrophoresed, the proteins were transferred onto a PVDF membrane by using a Bio-Rad western blot analysis apparatus. The membrane was incubated with blocking buffer for $1.5 \mathrm{~h}$ at room temperature and then incubated overnight at $4^{\circ} \mathrm{C}$ with the primary polyclonal antibodies against $\mathrm{p} 53$, Bax, caspase-3 and Bcl-2, followed by incubation with corresponding secondary antibodies. Specific protein bands were visualized with an ECL advanced western blot analysis detection kit (Merck Millipore, Billerica, MA, USA).

Statistical analysis. Data were shown as means \pm SEM. Statistical significance between two groups was tested by Student's t-test. Statistical significance between multiple groups was assessed by one-way ANOVA followed by Tukey's test. All statistical analysis were performed by the GraphPad Prism (version 6; GraphPad Software Inc., La Jolla, CA, USA). $\mathrm{P}<0.05$ was considered to be statistically significant.

\section{Results}

The effect of DSS treatment on cell viability in ALD-treated cardiomyocytes. To study whether DSS was able to protect against cardiac injury induced by ALD in vitro. Firstly, determined the effects of DSS on cell growth of cardiomyocytes. The cardiomyocytes were exposed to DSS $(0.01,0.1,1.0$ and $10.0 \mu \mathrm{mol} / \mathrm{l}$ ) for $12 \mathrm{~h}$ and as shown in Fig. 2A that the concentration of DSS from 0.01-1.0 $\mu \mathrm{mol} / 1$ no significant cell growth changes were found compared with the control group (P>0.05). However, treatment with $10 \mu \mathrm{mol} / \mathrm{l} \mathrm{DSS}$ resulted in a small but significant decrease in cell growth, suggesting that DSS may be cytotoxic in myocardial cells at high concentrations. Next, the cells were subjected to ALD (0.1-100.0 $\mu \mathrm{mol} / \mathrm{l})$ for $12 \mathrm{~h}$ or ALD $10.0 \mu \mathrm{mol} / 1$ for $0-24 \mathrm{~h}$. Compared with control group, when exposed to ALD $10.0 \mu \mathrm{mol} / 1$ for $12 \mathrm{~h}$ can significantly decrease the cell growth of cardiomyocytes and showed a concentration-dependent manner or time-dependent 
A

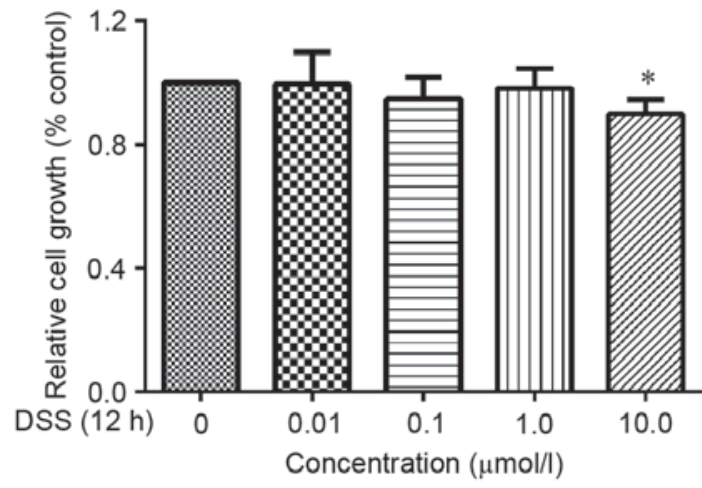

C

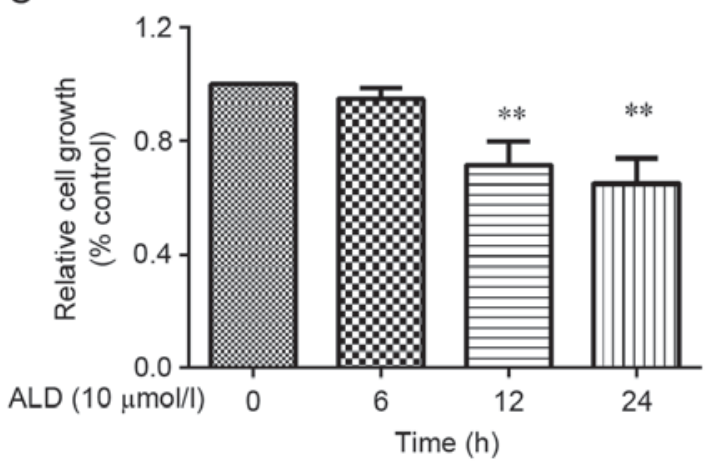

B

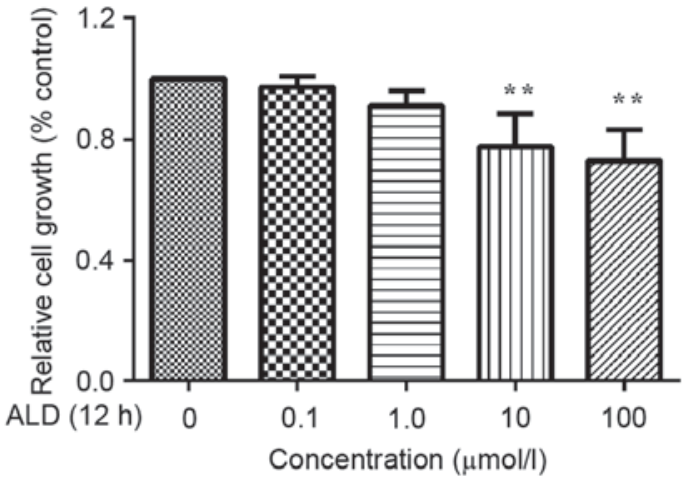

D

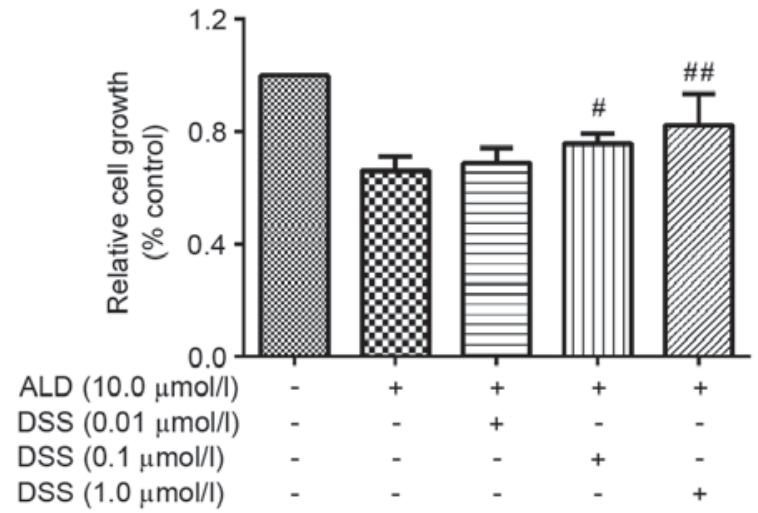

Figure 2. Effect of DSS treatment on cell viability of ALD-treated cardiomyocytes. (A) Cells were incubated with the different concentrations of DSS for 12 h; (B) cells were incubated with the different concentrations of ALD for $12 \mathrm{~h}$; (C) cells were incubated with the concentrations of ALD at $10 \mu \mathrm{mmol} / \mathrm{l}$ for $0-24 \mathrm{~h}$; (D) cells were subjected to ALD $(10.0 \mu \mathrm{mol} / \mathrm{l})$ treatment in the absence or presence of DSS $(0.01-1.0 \mu$ mol/1). After treatment, the cell growth was assayed by the MTT method. Results were expressed as mean \pm SEM from six independent experiments. ${ }^{*} \mathrm{P}<0.05,{ }^{* *} \mathrm{P}<0.01$ vs. control; ${ }^{\#} \mathrm{P}<0.05$ and ${ }^{\# \#} \mathrm{P}<0.01 \mathrm{vs}$. ALD alone. DSS, danshensu; ALD, aldosterone.

fashion (Fig. 2B and C). In the following experiment, cells were subjected to ALD $(10.0 \mu \mathrm{mol} / \mathrm{l})$ treatment in the absence or presence of DSS $(0.01-1.0 \mu \mathrm{mol} / \mathrm{l})$. ALD treatment significantly decreased cell growth $(\mathrm{P}<0.05$, compared with the control group; Fig. 2D), while DSS (0.1 and $1.0 \mu \mathrm{mol} / \mathrm{l})$ treatment for $12 \mathrm{~h}$ resulted in a significant increase in cell growth, in a concentration-dependent manner $(\mathrm{P}<0.05$, compared with the ALD group; Fig. 2D). However, $0.01 \mu \mathrm{mol} / 1 \mathrm{DSS}$ had almost no effect on improving the cell growth $(\mathrm{P}>0.05$ vs. ALD group).

Treatment with DSS decreased the leakage of $\mathrm{LDH}$ in ALD-induced cardiomyocytes. $\mathrm{LDH}$ is an oxidoreductase which catalyzes the interconversion of lactate and pyruvate. Cytotoxic compounds often impair cell membrane integrity by inducing cell apoptosis or necrosis. LDH is also served as a bio-maker of cellular membrane injury. There was a significant increase in LDH leakage ratio in cells exposed to $10 \mu \mathrm{mol} / 1 \mathrm{ALD}$ alone for $12 \mathrm{~h}(\mathrm{P}<0.01$ compared with the control group). However, the level of LDH leakage ratio was significantly reduced in cells pre-treated with DSS and in a concentration-dependent manner (Fig. 3).

Treatment with DSS prevented the cell apoptosis induced by ALD treatment in cardiomyocytes. To examine whether DSS has any effect on ALD-induced apoptosis in cardiomyocytes,

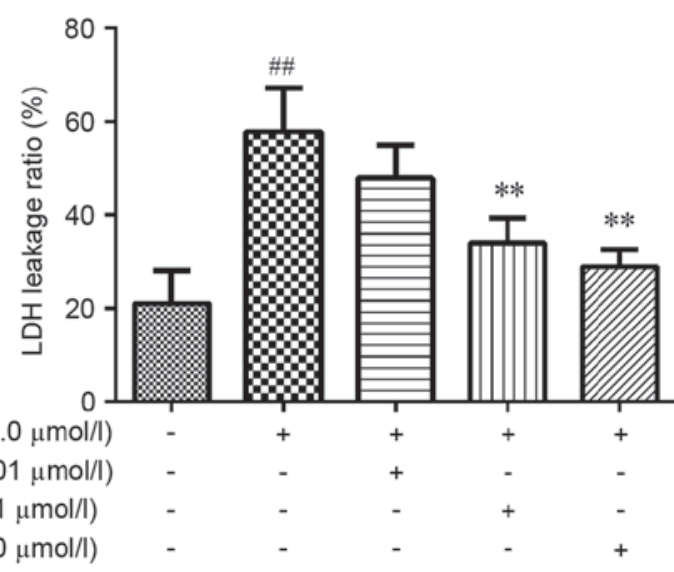

Figure 3. Inhibited effects of DSS on ALD-induced cardiomyocytes LDH release. An equal number of cells were pre-treated with DSS $(0.01,0.1$ or $1.0 \mu \mathrm{mol} / \mathrm{l})$ for $2 \mathrm{~h}$ and then cells were stimulated with ALD $(10.0 \mu \mathrm{mol} / \mathrm{l})$ for $12 \mathrm{~h}$. At the end of the incubation period, LDH release was assayed. Results were expressed as mean \pm SEM from six independent experiments. ${ }^{\#} \mathrm{P}<0.01$ vs. control; ${ }^{* *} \mathrm{P}<0.01$ compared with ALD alone. DSS, danshensu; ALD, aldosterone; LDH, lactate dehydrogenase.

the present study performed by flow cytometry. Results showed that ALD treatment increased the percentage of apoptotic cells ( $\mathrm{P}<0.05$, compared with control group). Compared with the ALD group, DSS treatment attenuated the apoptosis 

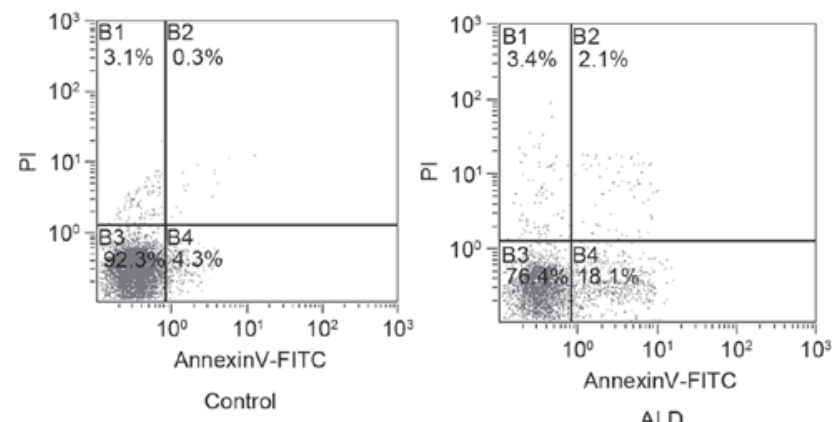

ALD

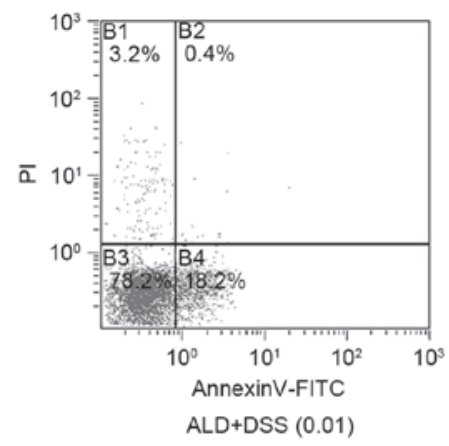

ALD+DSS $(0.01$
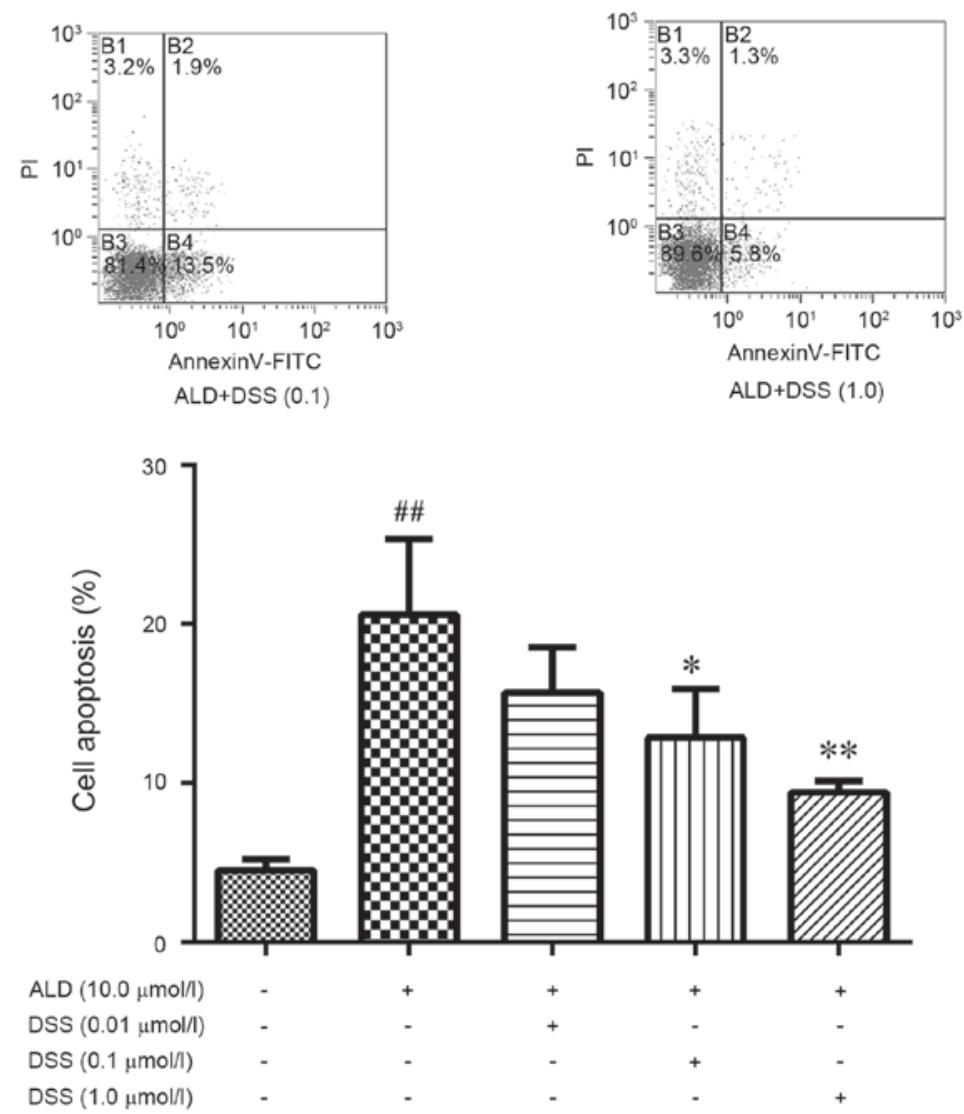

Figure 4. Impacts of DSS on ALD-induced cardiomyocytes apoptosis by Annexin V/PI staining. Cells were pre-treated with DSS $(0.01,0.1$ or $1.0 \mu$ mol/l) for $2 \mathrm{~h}$ and then were stimulated with ALD $(10.0 \mu \mathrm{mol} / \mathrm{l})$ for $12 \mathrm{~h}$. At the end of the incubation period, the cells were then prepared for Annexin V/PI staining. The data expressed as \% apoptotic cells (lower right quadrant plus upper right quadrant). Results were expressed as mean \pm SEM from three independent experiments, ${ }^{\# \#} \mathrm{P}<0.01$ vs. control; ${ }^{*} \mathrm{P}<0.05$ and ${ }^{* *} \mathrm{P}<0.01$ compared with ALD alone. DSS, danshensu; ALD, aldosterone; FITC, fluorescein isothiocyanate.

of cardiomyocytes, in a dose-dependent manner $(\mathrm{P}<0.05)$. In conclusion, these data confirmed that exposure of the cardiomyocytes to ALD induced cell apoptosis, however, pretreatment with DSS reversed this effect and protected the cardiomyocytes (Fig. 4).

The effect of DSS treatment on cleaved caspase-3, Bax and $B c l-2$ proteins expression in $A L D$-treated cardiomyocytes. To further investigate whether the protective effect of DSS, the protein levels of pro-apoptotic caspase-3, Bax, and anti-apoptotic Bcl-2 were measured using western blot analysis. As shown in Fig. 5, the protein expression of caspase-3, and Bax in the ALD group was significantly upregulated, compared with that in the control group $(\mathrm{P}<0.05)$. However, DSS decreased the expression of caspase- 3 and Bax, compared with the ALD group $(\mathrm{P}<0.05)$. In addition, conversely, ALD produced a significant decrease in the expression of $\mathrm{Bcl}-2(\mathrm{P}<0.05$, compared with control group). While, DSS treatment upregulated the ratio of $\mathrm{Bcl}-2$ ( $\mathrm{P}<0.05$, compared with ALD group). The results suggested that the protective effects of DSS were associated with the downregulation of caspase- 3 and Bax, and upregulation the expression of $\mathrm{Bcl}-2$.

Protective effect of DSS on ALD-induced cardiomyocytes injury via interfering p53 signaling pathway. Fig. 6A showed that pretreatment of DSS and p53 specific inhibitor pifithrin- $\alpha$ alone or in combination can decrease the level of p53 in ALD-induced cardiomyocytes $(\mathrm{P}<0.05$, compared with ALD group). Further study showed that DSS and pifithrin- $\alpha$ alone or in combination can downregulate ALD-induced the expression of caspase- 3 and Bax as well as upregulate the level of Bcl-2 in compare with ALD alone (Fig. 6B). 

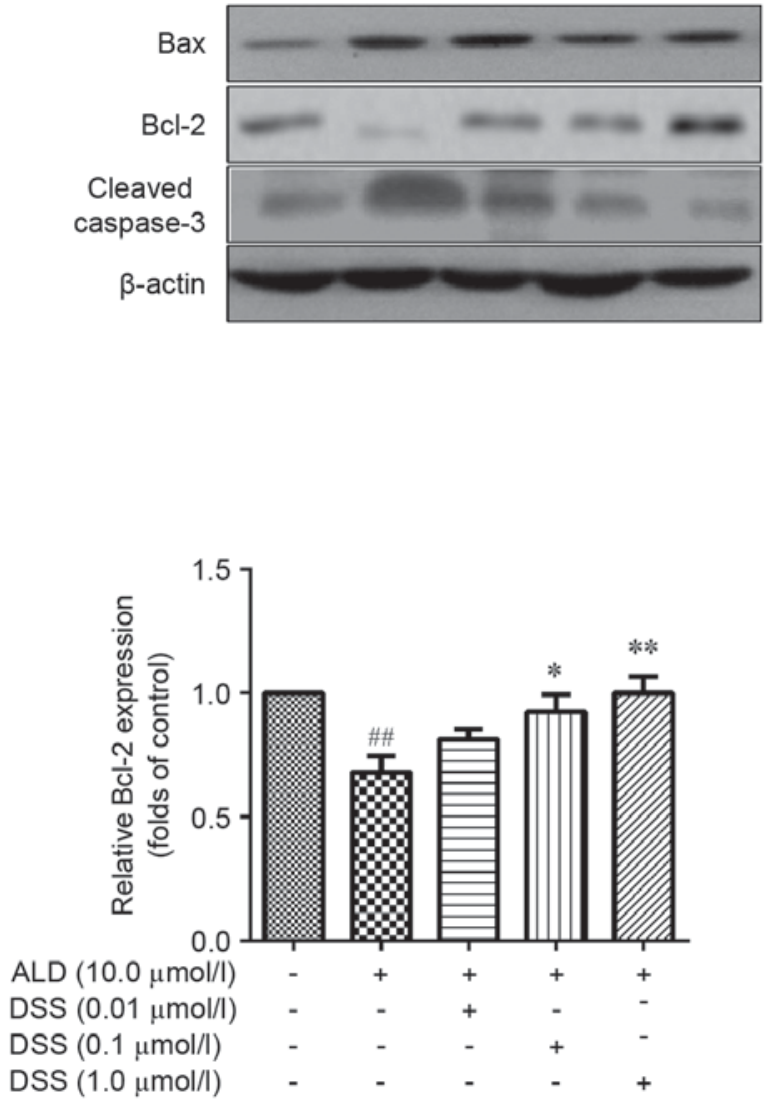
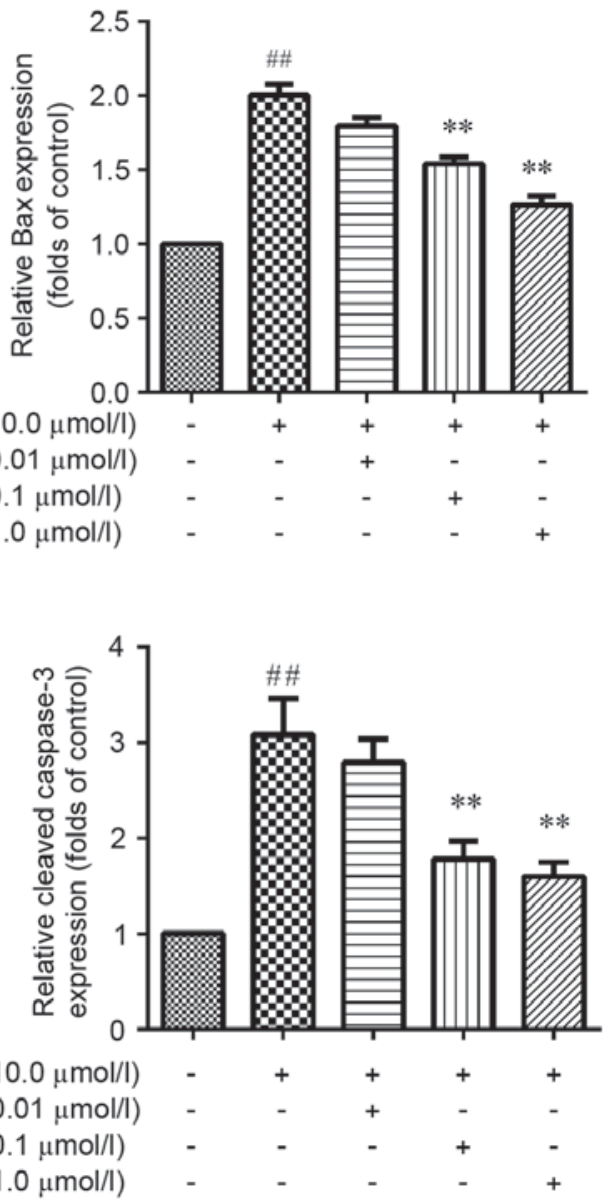

Figure 5. Regulation of DSS on ALD-induced Bax, Bcl-2 and cleaved caspase-3 levels in cardiomyocytes. The cells were pre-treated with DSS (0.01, 0.1 or $1.0 \mu \mathrm{mol} / 1)$ for $2 \mathrm{~h}$ and then were stimulated with ALD $(10.0 \mu \mathrm{mol} / 1)$ for $12 \mathrm{~h}$. At the end of the incubation period, each protein level was analyzed by western blot analysis. Levels of protein are shown as folds of control from three independent experiments and expressed as mean $\pm \mathrm{SEM}$. ${ }^{\# \prime} \mathrm{P}<0.01 \mathrm{vs}$. control; ${ }^{*} \mathrm{P}<0.05$ and ${ }^{* *} \mathrm{P}<0.01$ compared with ALD alone. DSS, danshensu; ALD, aldosterone; Bcl-2, B-cell lymphoma-2.

\section{Discussion}

In the present study, we demonstrated that DSS has a protective effect on the ALD induced cardiomyocytes injury. The protective effects involved in decreasing the leakage of $\mathrm{LDH}$ as well as inhibit the expression of apoptosis related protein via p53 pathway.

Traditional Chinese medicines and their ingredients have been used as the most important therapeutic agents in China from times immemorial. DSS, a water-soluble constituent of S. miltiorrhiza (Danshen), is well-recognized for its cardiovascular activity $(14,15)$. DSS was previously reported to protect the heart against I/R injury by reducing ROS generation and inhibiting cell apoptosis (16). While ALD is a mineralocorticoid hormone which regulates sodium and potassium transports in the epithelial cells of renal tubules (17). Excess ALD not only causes the abnormal water homeostasis, but also increases the risk of cardiovascular events independent of hypertension $(18,19)$. ALD also plays a critical role in the process of heart failure, and heart is one of direct targets of ALD, which can provoke hypertrophy and apoptosis of cardiomyocytes $(20,21)$. In this research, we found a protective effect of DSS in ALD treated cardiomyocytes; this protective effect is of signally important, because of cardiomyocytes loss including necrosis and apoptosis is one of the most important reason of heart failure.
As we all known that apoptosis, a form of programmed cell death, can occur in a wide range of physiological and pathological situations (22-24). It is characterized by cell shrinkage, programmed DNA degradation, cytoplasmic cytochrome $c$ release increased and activation of caspases. P53 plays a key role in DNA damage-induced apoptosis which aims at its transcriptional target pro-apoptotic Bax or translocates to mitochondria to interact with anti-apoptotic Bcl-2 in non-transcriptional way. The Bcl-2 family proteins are important regulators of apoptosis. Anti-apoptotic members such as Bcl-2 promote survival by inhibiting the function of the pro-apoptotic Bax proteins $(25,26)$. Furthermore, activated caspase-3 in the mitochondrial apoptotic pathway can lead to loss of ATP and ROS generation (27,28). The abnormal release of $\mathrm{LDH}$ is an index of plasma membrane damage and cell apoptosis (29). In the present research we found that DSS could decrease the release of $\mathrm{LDH}$ and upregulate the expression of apoptosis regulator $\mathrm{Bcl}-2$, as well as downregulate the protein of Bax and a decrease phenomenon of protein caspase-3 in ALD-treated cardiomyocytes when co-culture with DSS. Although, there exists few reports about the pro-apoptosis effect of ALD via p53 signaling pathway, the present research indicated that p53 signaling pathway might involve in the pro-apoptosis effect of ALD in cardiomyocytes and another protective mechanism of DSS might partly through interfering p53 signaling pathway. 
A

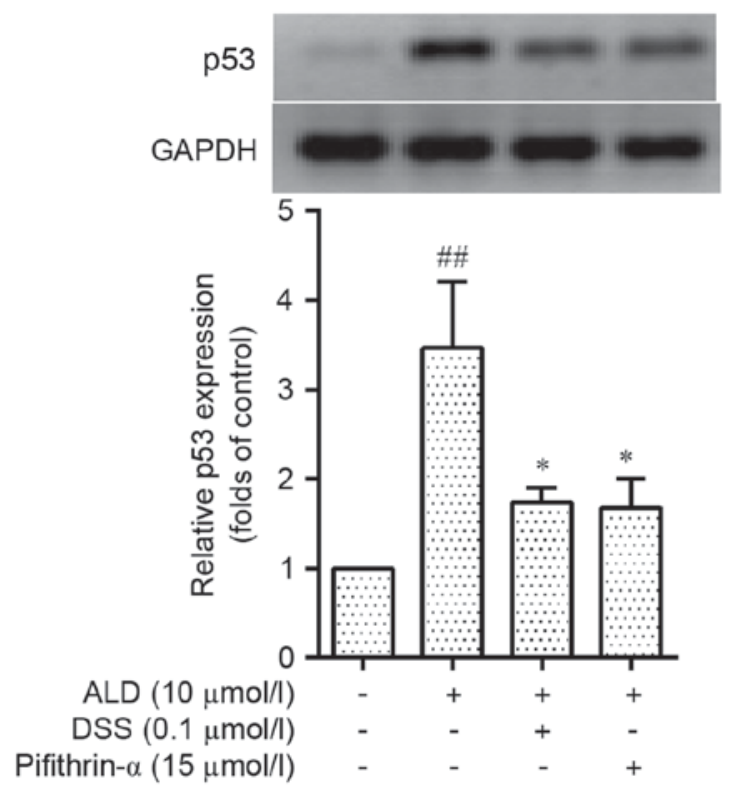

B
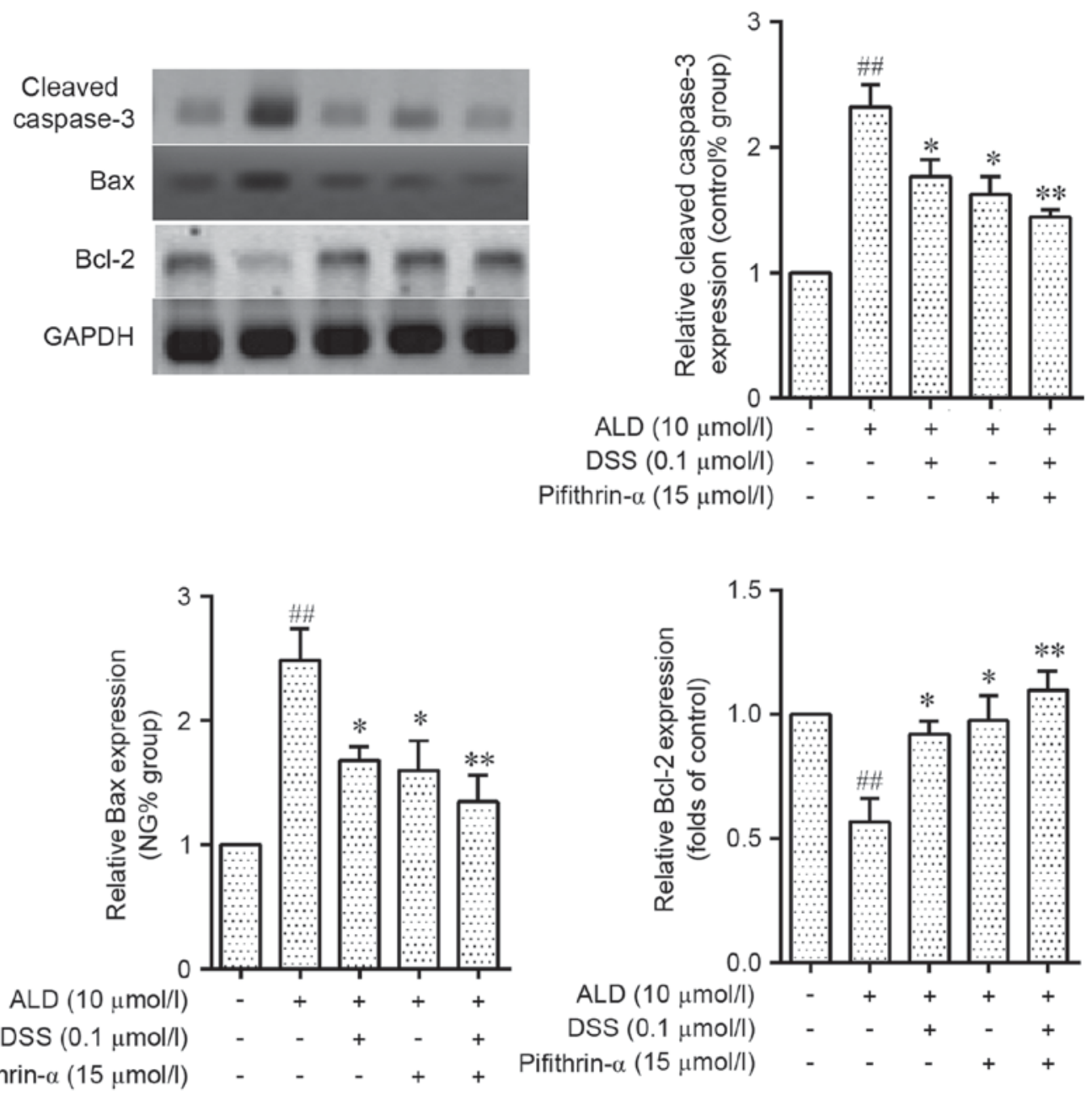

Figure 6. Involvement of p53 pathway in ALD-induced cardiomyocytes injury. The cells were pre-treated with DSS and p53 specific inhibitor pifithrin- $\alpha$ alone or in combination for $2 \mathrm{~h}$ and then were stimulated with ALD $(10.0 \mu \mathrm{mol} / \mathrm{l})$ for $12 \mathrm{~h}$. At the end of the incubation period, each protein level was analyzed by western blot analysis. (A) The expression of p53 protein; (B) the expression of cleaved caspase-3, Bax and Bcl-2. Levels of protein are shown as folds of control from three independent experiments and expressed as mean \pm SEM. ${ }^{\# \#} \mathrm{P}<0.01$ vs. control; ${ }^{*} \mathrm{P}<0.05$ and ${ }^{* *} \mathrm{P}<0.01$ compared with ALD alone. ALD, aldosterone; DSS, danshensu; Bcl-2, B-cell lymphoma-2.

In conclusion, DSS could protect cardiomyocytes from the injury of ALD by effectively alleviating the plasma membrane damage as well as decrease the level of Bax and caspase- 3 and increase the expression of Bcl-2. This mechanism mainly 
operates through interfering p53 pathway. The present study provides a new evidence for the potential effects of DSS in treating cardiovascular diseases.

\section{References}

1. Hussein AA, Gottdiener JS, Bartz TM, Sotoodehnia N, deFilippi C, Dickfeld T, Deo R, Siscovick D, Stein PK and Lloyd-Jones D: Cardiomyocyte injury assessed by a highly sensitive troponin assay and sudden cardiac death in the community: The Cardiovascular Health Study. J Am Coll Cardiol 62 : 2112-2120, 2013.

2. Mueller C: Biomarkers and acute coronary syndromes: An update. Eur Heart J 35: 552-556, 2014.

3. Taqueti VR, Everett BM, Murthy VL, Gaber M, Foster CR, Hainer J, Blankstein R, Dorbala S and Di Carli MF: Interaction of impaired coronary flow reserve and cardiomyocyte injury on adverse cardiovascular outcomes in patients without overt coronary artery disease. Circulation 131: 528-535, 2015.

4. Messaoudi S, Gravez B, Tarjus A, Pelloux V, Ouvrard-Pascaud A, Delcayre C, Samuel J, Launay JM, Sierra-Ramos C, Alvarez de la Rosa D, et al: Aldosterone-specific activation of cardiomyocyte mineralocorticoid receptor in vivo. Hypertension 61 : 361-367, 2013.

5. Xiao TT, Wang YY, Zhang Y, Bai CH and Shen XC: Similar to spironolactone, oxymatrine is protective in aldosterone-induced cardiomyocyte injury via inhibition of calpain and apoptosis-inducing factor signaling. PLoS One 9: e88856, 2014.

6. Hattori T, Murase T, Sugiura Y, Nagasawa K, Takahashi K, Ohtake M, Ohtake M, Miyachi M, Murohara T and Nagata K: Effects of salt status and blockade of mineralocorticoid receptors on aldosterone-induced cardiac injury. Hypertens Res 37: 125-133, 2014

7. Li H, Song F, Duan LR, Sheng JJ, Xie YH, Yang Q, Chen Y, Dong QQ, Zhang BL and Wang SW: Paeonol and danshensu combination attenuates apoptosis in myocardial infarcted rats by inhibiting oxidative stress: Roles of Nrf2/HO-1 and PI3K/Akt pathway. Sci Rep 6: 23693, 2016.

8. Cui G, Shan L, Hung M, Lei S, Choi I, Zhang Z, Yu P, Hoi P, Wang Y and Lee SM: A novel Danshensu derivative confers cardioprotection via PI3K/Akt and Nrf2 pathways. Int J Cardiol 168: 1349-1359, 2013.

9. Cao Y, Chai JG, Chen YC, Zhao J, Zhou J, Shao JP, Ma C, Liu XD and Liu XQ: Beneficial effects of danshensu, an active component of Salvia miltiorrhiza, on homocysteine metabolism via the trans-sulphuration pathway in rats. Br J Pharmacol 157: 482-490, 2009

10. Yu C, Qi D, Lian W, Li QZ, Li HJ and Fan HY: Effects of danshensu on platelet aggregation and thrombosis: In vivo arteriovenous shunt and venous thrombosis models in rats. PLoS One 9: e110124, 2014

11. Li H, Xie YH, Yang Q, Wang SW, Zhang BL, Wang JB, Cao W, Bi LL, Sun JY, Miao S, et al: Cardioprotective effect of paeonol and danshensu combination on isoproterenol-induced myocardial injury in rats. PLoS One 7: e48872, 2012.

12. Zhou X, Chan SW, Tseng HL, Deng Y, Hoi PM, Choi PS, Or PM, Yang JM, Lam FF, Lee SM, et al: Danshensu is the major marker for the antioxidant and vasorelaxation effects of Danshen (Salvia miltiorrhiza) water-extracts produced by different heat water-extractions. Phytomedicine 19: 1263-1269, 2012.

13. Xiao T, Zhang Y, Wang Y, Xu Y, Yu Z and Shen X: Activation of an apoptotic signal transduction pathway involved in the upregulation of calpain and apoptosis-inducing factor in aldosterone-induced primary cultured cardiomyocytes. Food Chem Toxicol 53: 364-370, 2013.
14. Yang RX, Huang SY, Yan FF, Lu XT, Xing YF, Liu Y, Liu YF and Zhao YX: Danshensu protects vascular endothelia in a rat model of hyperhomocysteinemia. Acta Pharmacol Sin 31: 1395-1400, 2010.

15. Yin Y, Guan Y, Duan J, Wei G, Zhu Y, Quan W, Guo C, Zhou D, Wang Y, Xi M and Wen A: Cardioprotective effect of Danshensu against myocardial ischemia/reperfusion injury and inhibits apoptosis of H9c2 cardiomyocytes via Akt and ERK1/2 phosphorylation. Eur J Pharmacol 699: 219-226, 2013.

16. Meng Y, Li WZ, Shi YW, Zhou BF, Ma R and Li WP: Danshensu protects against ischemia/reperfusion injury and inhibits the apoptosis of $\mathrm{H} 9 \mathrm{c} 2$ cells by reducing the calcium overload through the p-JNK-NF-кB-TRPC6 pathway. Int J Mol Med 37: 258-266, 2016.

17. Beygui F, Cayla G, Roule V, Roubille F, Delarche N, Silvain J, Van Belle E, Belle L, Galinier M, Motreff P, et al: Early aldosterone blockade in acute myocardial infarction: The ALBATROSS Randomized Clinical Trial. J Am Coll Cardiol 67: 1917-1927, 2016.

18. Baudrand R, Pojoga LH, Vaidya A, Garza AE, Vöhringer PA, Jeunemaitre X, Hopkins PN, Yao TM, Williams J, Adler GK, et al: Statin use and adrenal aldosterone production in hypertensive and diabetic subjects. Circulation 132: 1825-1833, 2015.

19. Daimon M, Kamba A, Murakami H, Takahashi K, Otaka H, Makita K, Yanagimachi M, Terui K, Kageyama K, Nigawara T, et al: Association between pituitary-adrenal axis dominance over the renin-angiotensin-aldosterone system and hypertension. J Clin Endocrinol Metab 101: 889-897, 2016.

20. Cannavo A, Liccardo D, Eguchi A, Elliott KJ, Traynham CJ, Ibetti J, Eguchi S, Leosco D, Ferrara N, Rengo G and Koch WJ: Myocardial pathology induced by aldosterone is dependent on non-canonical activities of $\mathrm{G}$ protein-coupled receptor kinases. Nat Commun 7: 10877, 2016

21. Mummidi S, Das NA, Carpenter AJ, Kandikattu H, Krenz M, Siebenlist U, Valente AJ and Chandrasekar B: Metformin inhibits aldosterone-induced cardiac fibroblast activation, migration and proliferation in vitro, and reverses aldosterone+salt-induced cardiac fibrosis in vivo. J Mol Cell Cardiol 98: 95-102, 2016.

22. Spencer SL and Sorger PK: Measuring and modeling apoptosis in single cells. Cell 144: 926-939, 2011.

23. Scarabelli T, Stephanou A, Rayment N, Pasini E, Comini L, Curello S, Ferrari R, Knight R and Latchman D: Apoptosis of endothelial cells precedes myocyte cell apoptosis in ischemia/reperfusion injury. Circulation 104: 253-256, 2001.

24. Flusberg DA and Sorger PK: Surviving apoptosis: Life-death signaling in single cells. Trends Cell Biol 25: 446-458, 2015.

25. Hada M, Subramanian C, Andrews PC and Kwok RP: Cytosolic Ku70 regulates Bax-mediated cell death. Tumour Biol 37: 13903-13914, 2016

26. Lin X, Sun R, Zhao X, Zhu D, Zhao X, Gu Q, Dong X, Zhang D, Zhang Y, Li Y and Sun B: C-myc overexpression drives melanoma metastasis by promoting vasculogenic mimicry via c-myc/snail/Bax signaling. J Mol Med (Berl) 95: 53-67, 2017.

27. López-Furelos A, Leiro-Vidal JM, Salas-Sánchez AÁ, Ares-Pena FJ and López-Martín ME: Evidence of cellular stress and caspase-3 resulting from a combined two-frequency signal in the cerebrum and cerebellum of sprague-dawley rats. Oncotarget 7: 64674-64689, 2016.

28. Taparia SS and Khanna A: Procyanidin-rich extract of natural cocoa powder causes ROS-mediated caspase-3 dependent apoptosis and reduction of pro-MMP-2 in epithelial ovarian carcinoma cell lines. Biomed Pharmacother 83: 130-140, 2016.

29. Stankovic Stojanovic K and Lionnet F: Lactate dehydrogenase in sickle cell disease. Clin Chim Acta 458: 99-102, 2016. 